\title{
Demographic and Clinical Profiles of Blood Transfusion Recipients at a Teaching and Referral Hospital in Kenya
}

\author{
Japheth C. Kipkulei ${ }^{*}$, Nathan Buziba1, Simeon Mining², Hellen Jepngetich ${ }^{3}$ \\ ${ }^{1}$ Department of Haematology and Blood Transfusion, School of Medicine, College of Health Sciences, Moi University, \\ Eldoret, Kenya \\ ${ }^{2}$ Department of Immunology, School of Medicine, College of Health Sciences, Moi University, Eldoret, Kenya \\ ${ }^{3}$ Department of Environmental Health, School of Public Health, College of Health Sciences, Moi University, Eldoret, Kenya \\ Email: *jkipkulei@gmail.com
}

How to cite this paper: Kipkulei, J.C., Buziba, N., Mining, S. and Jepngetich, H. (2019) Demographic and Clinical Profiles of Blood Transfusion Recipients at a Teaching and Referral Hospital in Kenya. Open Journal of Blood Diseases, 9, 30-40. https://doi.org/10.4236/ojbd.2019.91004

Received: February 1, 2019

Accepted: March 10, 2019

Published: March 13, 2019

Copyright (c) 2019 by author(s) and Scientific Research Publishing Inc. This work is licensed under the Creative Commons Attribution International License (CC BY 4.0).

http://creativecommons.org/licenses/by/4.0/

\begin{abstract}
Background: Blood transfusion is an essential component of modern health care. It is required universally to manage various medical, surgical and obstetric conditions. Establishing the profiles of blood recipients would help in predicting the long term needs of blood transfusion as changing patterns of populations, diseases and health care will result in changing demands for blood and blood components. The objective of the study was to determine the pattern of blood use in terms of demographic and clinical profiles of the recipients. Methods: A hospital based medical chart review of 384 patients who were transfused from June 2013 to November 2013 was carried out. Systematic random sampling method was used; data were collected using a structured data collection form and was analyzed using frequency tables. Results: The median age of the recipients was 31.5 years (IQR 13, 45.8) and the range was 0 to 89 years. Females comprised $55.2 \%$ of the recipients, of which $57.7 \%$ were in the reproductive age group (15 - 49 years). The majority of the recipients $(60 \%)$ were from surgical and medical wards. The main indication of the transfusion was anaemia $(62.8 \%)$ and most of the transfused patients were being treated for neoplasms (23.2\%), pregnancy and childbirth related conditions (11.7\%), injuries (11.5\%) and infections (11.4\%). Conclusion: Majority of the transfused patients were relatively young and were females. Anemia was the main indication of the transfusion and most of the transfused recipients presented with neoplasms, pregnancy and childbirth related conditions, infections and injuries.
\end{abstract}

\section{Keywords}

Blood Transfusion, Blood Use, Presenting Condition, International 
Classification of Disease (ICD)

\section{Introduction}

Blood transfusion is an essential component of modern health care. It is required universally to manage various medical, surgical and obstetric conditions [1]. Blood, though vital in health care, is a scarce resource, costly and its use can be associated with infectious and non-infectious risks. In order to improve the transfusion practice, review and continuous evaluation of blood usage is necessary [2]. This involves determining the pattern of blood use, the demographic characteristics of the transfusion recipients, the clinical conditions and the wards requiring blood transfusion in a population. Evaluation of blood requisition and utilization is crucial in assessing the present and future demands for blood and avoiding unnecessary requests and transfusions [3]. Various studies on blood use have demonstrated different profiles in terms of demographics, diagnoses and clinical indications. These differences might be due to varying geographical location and methodological heterogeinity of these studies [4].

The demographic and clinical profiles of the recipients of blood and blood components differ between developed and developing countries. According to WHO [1], blood transfusion in developed countries is commonly used to support advanced medical and surgical procedures, including trauma, cardiovascular surgery, neurosurgery, transplantation etc.; while in developing countries, a much greater proportion of blood is used to treat women with obstetric emergencies and children suffering from severe anemia, often resulting from malaria and malnutrition.

Data on blood use is helpful in resource limited settings in which there are always competing needs for scarce resources [5]. Information on blood utilization will assist in establishing clinical practice guidelines, strategizing on new donor recruitment, streamlining resources for the benefit of the patient and conducting cost effective analysis [3]. This study aimed at determining the demographic and clinical characteristics of blood transfusion recipients and the pattern of blood use in a national teaching and referral hospital.

\section{Methodology}

This was a retrospective hospital-based chart review carried out at Moi Teaching and Referral Hospital which is a 900-bed capacity hospital located in Eldoret town, Kenya and it serves western Kenya, parts of Southern Uganda and South Sudan.

The study targeted patients who were admitted to the general wards of the hospital and were transfused whole blood or packed red cells between the months of June to November 2013. A sample of 384 patient charts was sampled using systematic random sampling method. 
Data was collected using a structured data collection form and information was extracted from the clinical notes, laboratory request forms and the nursing notes. The data collected included the recipient's age, gender, clinical department, presenting condition (diagnosis) and blood and blood component transfused. The International Classification of Diseases (ICD-10) version was used for classification of the presenting conditions requiring transfusion of blood and blood components. The primary and the secondary ICD-10 codes were matched with the clinical details and diagnosis obtained from the patient clinical notes and request forms to select the most appropriate condition requiring transfusion. The diagnoses were then grouped into broad categories according to the 21 (I-XXI) chapters of ICD-10.

The data was entered into SPSS software version 20, summarized and analyzed using frequency tables. Ethical clearance was obtained from Institutional Research and Ethical Committee (IREC) of Moi University and Moi Teaching and Referral Hospital. The patients' medical records were de-identified.

\section{Results}

\subsection{Demographic Characteristics of the Transfusion Recipients}

The median age of the patients (IQR) was $31.5(13,45.8)$ and the range was 0 to 89 years. The mean age (standard deviation) of the recipients was 31.3 (21.4). About $8.8 \%$ of the recipients were at least 65 years and $27.6 \%$ were below 15 years of age. Majority of the transfused patients were women $(55.2 \%, 212 / 384)$, with recipients in the reproductive age group ( 15 - 49 years) accounting for the majority, $55.7 \%$ (118/212). The distribution of the transfusion recipients according to age and sex is as shown in Table 1 and Figure 1.

\subsection{Clinical Profiles of the Transfusion Recipients}

The clinical characteristics of the recipients are as shown in Table 2. Of all the transfused patients, $30.5 \%$ (117) were admitted to the surgical wards while $29.2 \%$ (112) were in the medical department. Neoplasms accounted for the majority of

Table 1. The demographic characteristics of the transfusion recipients.

\begin{tabular}{|c|c|c|c|}
\hline \multirow{2}{*}{ Age group (years) } & \multirow{2}{*}{ Recipients, n (\%) } & \multicolumn{2}{|c|}{ Sex of recipient } \\
\hline & & Males, n (\%) & Females, n (\%) \\
\hline $0-4$ & $54(14.1)$ & $25(46.3)$ & $29(53.7)$ \\
\hline $5-14$ & $52(13.5)$ & $25(48.1)$ & 27 (51.9) \\
\hline $15-24$ & $31(8.1)$ & $8(25.8)$ & $23(74.2)$ \\
\hline $25-34$ & $78(20.3)$ & $31(39.7)$ & $47(60.3)$ \\
\hline $35-44$ & $71(18.5)$ & 34 (47.9) & $37(52.1)$ \\
\hline $45-54$ & $41(10.7)$ & $19(46.3)$ & $22(53.7)$ \\
\hline $55-64$ & $23(6.0)$ & $12(52.2)$ & $11(47.8)$ \\
\hline$\geq 65$ & $34(8.8)$ & $18(52.9)$ & $16(47.1)$ \\
\hline
\end{tabular}


Table 2. Clinical profiles of the transfusion recipients.

\begin{tabular}{|c|c|c|}
\hline Clinical profiles & Frequency (n) & Percent $(\%)$ \\
\hline \multicolumn{3}{|l|}{ Clinical department } \\
\hline Medical & 112 & 29.2 \\
\hline Surgical & 117 & 30.5 \\
\hline Reproductive health & 75 & 19.5 \\
\hline Child health & 80 & 20.8 \\
\hline \multicolumn{3}{|l|}{ Presenting condition } \\
\hline Infectious and parasitic diseases (A00-B99) & 44 & 11.4 \\
\hline Neoplasms (C00-O48) & 89 & 23.2 \\
\hline Diseases of blood \& blood forming organs (D00-D89) & 31 & 8.1 \\
\hline Endocrine, nutritional and metabolic disease (E00-E90) & 13 & 3.4 \\
\hline Diseases of the nervous system $(\mathrm{G} 00=\mathrm{G} 99)$ & 2 & 0.5 \\
\hline Diseases of the circulatory system (I00-I99) & 3 & 0.8 \\
\hline Diseases of the respiratory system (J00-J99) & 4 & 1.0 \\
\hline Diseases of the digestive system (K00-K93) & 28 & 7.3 \\
\hline Diseases of the skin and subcutaneous tissues (L00-L99) & 3 & 0.8 \\
\hline Diseases of musculoskeletal system (M00-M99) & 6 & 1.6 \\
\hline Diseases of the genitourinary system (N00-N99) & 36 & 9.4 \\
\hline Pregnancy, childbirth \& Puerperium (O00-O99) & 45 & 11.7 \\
\hline Conditions in the perinatal period (P00-P99) & 27 & 7.0 \\
\hline Congenital malformations (Q00-99) & 9 & 2.3 \\
\hline Injuries (S00-T98) & 44 & 11.4 \\
\hline \multicolumn{3}{|l|}{ Indication of the transfusion } \\
\hline Unspecified anaemia & 241 & 62.8 \\
\hline Elective surgery & 56 & 14.6 \\
\hline Haemorrhage & 53 & 13.8 \\
\hline Indication not documented & 34 & 8.8 \\
\hline \multicolumn{3}{|l|}{ Blood groups } \\
\hline $\mathrm{A}^{+}-(-1)$ & 111 & 28.9 \\
\hline $\mathrm{A}^{-}$ & 7 & 1.8 \\
\hline $\mathrm{B}^{+}$ & 51 & 13.3 \\
\hline $\mathrm{B}^{-}$ & 2 & 0.5 \\
\hline $\mathrm{AB}^{+}$ & 15 & 3.9 \\
\hline $\mathrm{AB}^{-}$ & 2 & 0.5 \\
\hline $\mathrm{O}^{+}$ & 190 & 49.5 \\
\hline $\mathrm{O}^{-}$ & 6 & 1.6 \\
\hline
\end{tabular}

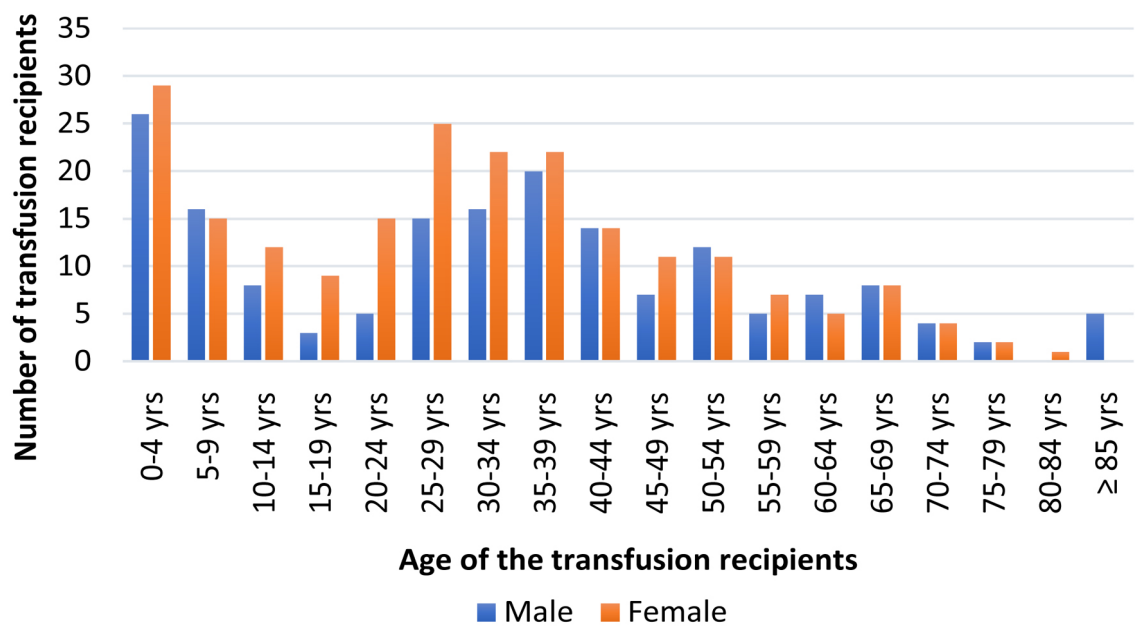

Figure 1. Distribution of the transfusion recipients according by age and sex. 
the presenting conditions for the recipients, $23.2 \%$ (89/384), of which $73 / 88$ (83.0\%) were malignant. This was followed by pregnancy and childbirth related cases $(12.5 \%)$, injuries (11.5\%) and infectious \& parasitic conditions (11.2\%). The top four broad diagnostic categories were further classified into four subcategories (Table 3).

The indication of the blood transfusion was classified into three broad categories: anaemia, haemorrhage and elective surgery. Majority of the recipients, 241 (62.8\%) had unspecified anaemia as the indication for blood transfusion while $56(14.6 \%)$ were transfused in preparation for elective surgery. Among the patients who were transfused because of hemorrhage, 34/53 (63\%) had obstetric/gynaecologic bleeding. The common blood group among the transfusion recipients was O Rhesus positive (49.5\%) and the least were blood groups B Rhesus negative $(0.5 \%)$ and $A B$ Rhesus negative (0.5\%).

\subsection{Distribution of Transfusion Recipients by Blood and Blood Component Transfused and Age and Sex}

Whole blood was transfused to $231(60.2 \%)$ of the recipients while PRBC was used by $153(39.8 \%)$ patients. Patients in the $20-49$ years age range utilized $48.4 \%(186 / 384)$ of all the blood and blood component, out of which $69.9 \%$ $(130 / 186)$ was whole blood. Whole blood was mostly transfused to women $(126 / 212,59.4 \%)$ and paediatric patients below the age of 9 years received $13.2 \%$ (28/212) of whole blood and $36.6 \%$ (56/153) of PRBC (Figure 2).

Table 3. The 16 most frequent ICD-10 diagnoses.

\begin{tabular}{|c|c|c|c|}
\hline $\begin{array}{c}\text { Broad } \\
\text { diagnostic } \\
\text { category }\end{array}$ & Four subcategories & $\begin{array}{l}\text { Number } \\
\text { of } \\
\text { recipients }\end{array}$ & $\begin{array}{c}\text { Percent } \\
(\%)\end{array}$ \\
\hline \multirow{4}{*}{ Neoplasms } & Malignant disorders of lymphoid and haematopoietic tissues & 18 & 4.6 \\
\hline & Benign neoplasms & 16 & 4.2 \\
\hline & Malignant neoplasms of female genital organs & 12 & 3.1 \\
\hline & Malignant neoplasms of digestive system & 10 & 2.6 \\
\hline \multirow{4}{*}{$\begin{array}{l}\text { Pregnancy, } \\
\text { childbirth } \\
\text { and the } \\
\text { puerperium }\end{array}$} & Abortion, unspecified & 11 & 2.7 \\
\hline & Postpartum haemorrhage & 8 & 2.1 \\
\hline & Antepartum haemorrhage, unspecified & 8 & 2.1 \\
\hline & Anaemia complicating pregnancy, unspecified & 7 & 1.8 \\
\hline \multirow{4}{*}{$\begin{array}{c}\text { Certain } \\
\text { infectious } \\
\text { and } \\
\text { parasitic } \\
\text { diseases }\end{array}$} & Human immunodeficiency (HIV) disease, unspecified & 25 & 6.5 \\
\hline & Malaria, unspecified & 10 & 2.6 \\
\hline & Visceral leishmaniasis & 4 & 1.0 \\
\hline & Tuberculosis & 3 & 0.8 \\
\hline \multirow{4}{*}{ Genitourinary } & Chronic kidney disease, unspecified & 23 & 6.0 \\
\hline & Obstructive uropathy and reflux uropathy, unspecified & 2 & 0.5 \\
\hline & Menorhagia & 2 & 0.5 \\
\hline & Benign prostatic hyperplasia & 2 & 0.5 \\
\hline
\end{tabular}




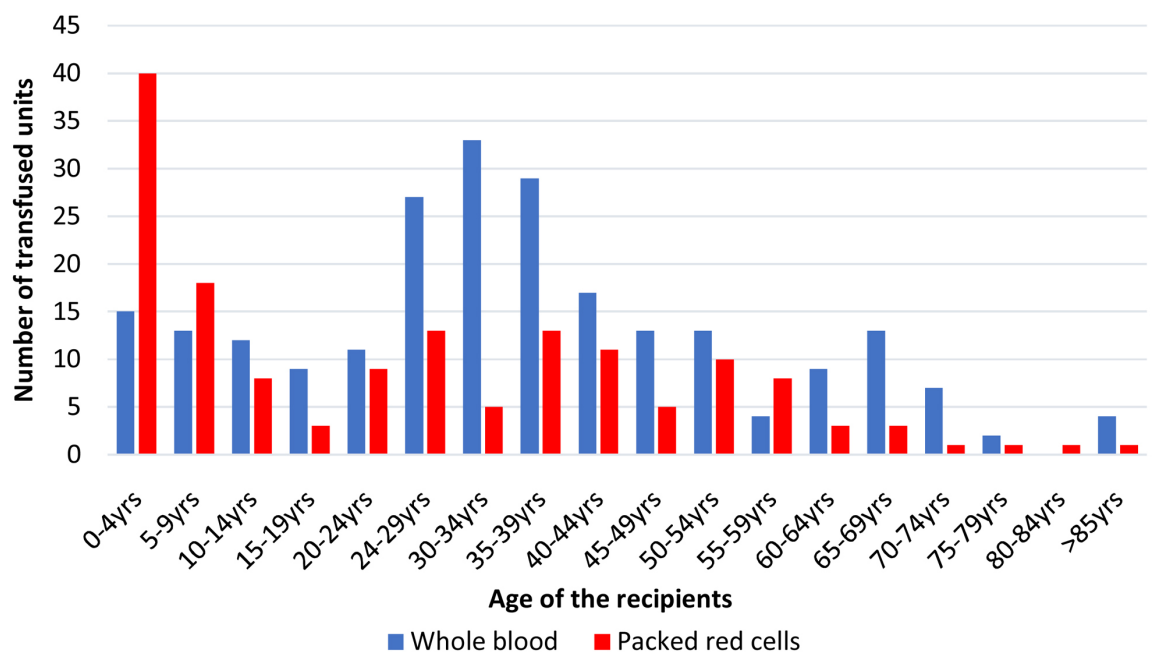

Figure 2. The distribution of transfusion recipients by blood and blood component used and age.

\subsection{Distribution of Recipients by Blood and Blood Component Transfused and the Clinical Department}

A higher proportion of blood and component utilized by recipients in the reproductive health department was whole blood $(76.0 \%, 56 / 75)$ and this was followed by recipients in surgical department $(69.2 \%, 81 / 117)$. Only $30 \%(24 / 80)$ of the recipients in child health department utilized whole blood. Packed red blood cells were transfused to $70 \%(56 / 80)$ of recipients in the child health department (Table 4).

\subsection{Distribution of Transfusion Recipients by Blood Component Transfused and Presenting Condition}

The proportion of whole blood accounted for $82 \%$ (37/45) of all the blood and blood component transfused to recipients who had pregnancy and child birth related conditions, followed by those with digestive system disorders 75\% (21/28). Of all the blood and blood component transfused to patients with conditions in the perinatal period, packed red blood cells accounted for $88.9 \%$ (24/27) (Table 5).

\subsection{Distribution of Transfusion Recipients by Blood and Blood Product Transfused and the Indication}

Whole blood was mainly used in patients with anaemia, accounting for $35.2 \%$ (135/384) of all the transfused units. A large proportion of whole blood was given to patients with haemorrhage $(73.6 \%, 39 / 53)$ as shown in Figure 3.

\section{Discussion}

In our findings, blood was used mainly by relatively young population of which the median age for the recipients was 31.5 years with patients in the $20-49$ years age range utilizing the highest proportion of the transfused units. This finding 
Table 4. The distribution of transfusion recipients by blood and blood component use and the clinical department.

\begin{tabular}{lccc}
\hline \multirow{2}{*}{ Clinical department } & Recipients, $\mathrm{n}(\%)$ & \multicolumn{2}{c}{ Blood and Blood component } \\
\cline { 3 - 4 } & & Whole blood, $\mathrm{n}(\%)$ & Packed red cells, $\mathrm{n}(\%)$ \\
\hline Medical & $112(29.2)$ & $69(61.6)$ & $43(38.4)$ \\
Surgical & $117(30.5)$ & $81(69.2)$ & $36(30.8)$ \\
Reproductive health & $75(19.5)$ & $57(76.0)$ & $18(24.0)$ \\
Child health & $80(20.8)$ & $24(30.0)$ & $56(70.0)$ \\
Total & $384(100)$ & $231(60.2)$ & $153(39.8)$ \\
\hline
\end{tabular}

Table 5. Distribution of recipients by blood and blood component use and the presenting condition.

\begin{tabular}{lccc}
\hline & & Blood and Blood component \\
\cline { 3 - 4 } \multicolumn{1}{c}{ Presenting condition } & Recipients, & Whole blood, & Packed red \\
& $\mathrm{n}(\%)$ & $\mathrm{n}(\%)$ & cells, n (\%) \\
\hline Infectious and parasitic & & $25(56.8)$ & $19(43.2)$ \\
Neoplasms & $44(11.4)$ & $55(61.8)$ & $34(38.2)$ \\
Diseases of blood & $89(23.2)$ & $16(51.6)$ & $15(48.4)$ \\
Endocrine, nutritional and metabolic disorders & $13(3.4)$ & $8(61.5)$ & $5(38.5)$ \\
Digestive system diseases & $28(7.3)$ & $21(75.0)$ & $7(25.0)$ \\
Genitourinary disorders & $36(9.4)$ & $25(69.4)$ & $11(30.6)$ \\
Pregnancyrelated conditions & $45(11.7)$ & $37(82.2)$ & $8(17.8)$ \\
Perinatal conditions & $27(7.0)$ & $3(11.1)$ & $24(88.9)$ \\
Injuries & $44(11.4)$ & $29(65.9)$ & $15(34.1)$ \\
Others & $27(7.0)$ & $12(44.4)$ & $15(55.6)$ \\
Total & $384(100)$ & $231(60.2)$ & $153(39.8)$ \\
\hline
\end{tabular}

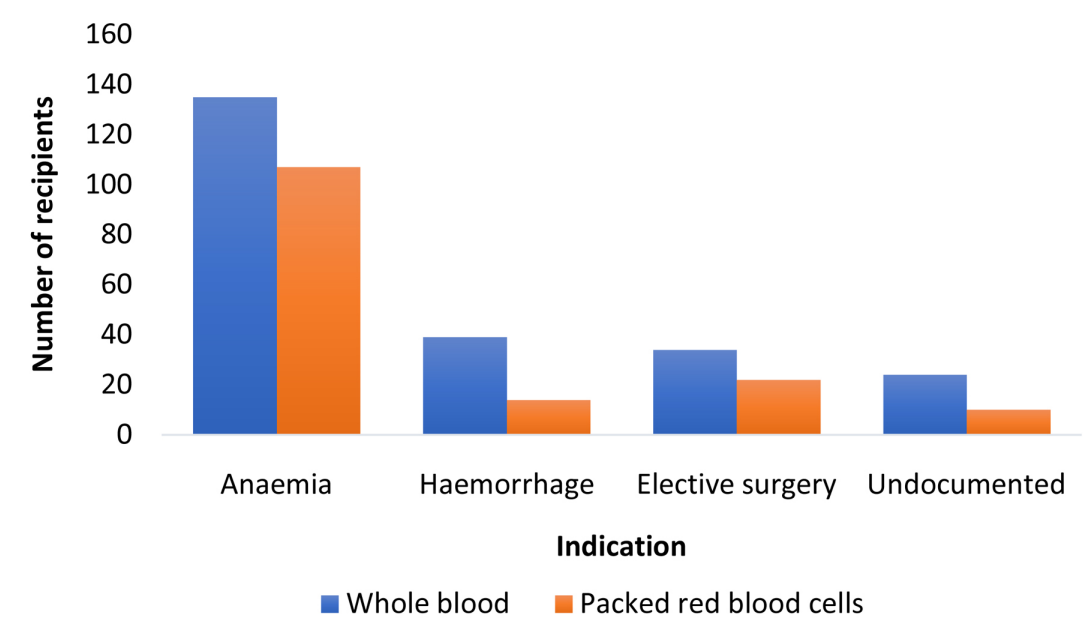

Figure 3. Distribution of transfusion recipients by blood and blood product used and the indication.

concurs with that of other studies from developing countries [5] [6] [7] [8] [9]. However, it varies from studies from developed countries [3] [10] [11]. This could be attributed to differences in age distribution of transfused patients in 
these countries, whereby in developing countries, most transfusions are utilized by younger patients while in the developed countries the elderly (65 years and above) patients are ones mostly transfused [12].

In terms of gender, females (55.2\%) utilized more blood transfusions than males, with those in the reproductive age group (15 - 49 years) accounting for the majority (118/212, 55.7\%). This observation is consistent with study findings from other sub-Saharan Africa countries where women receive more blood for pregnancy-related complications resulting from intra-partum and post-partum haemorrhage [5] [8] [13]. In our study, of all the patients admitted to the reproductive health department, $45.3 \%$ (34/75) were transfused due to obstetric/gynaecologic haemorrhage, out of which $61.8 \%$ (21/34) resulted from abortions, ante-partum and post-partum haemorrhage.

Whole blood was transfused to the majority of the transfusion recipients $(60.2 \%)$ and this result compares to the finding by Okoroiwu et al. [13] where $71.57 \%$ of the transfusion recipients received whole blood. This finding reflects common practice of requesting for whole blood in resource limited settings because of lack of facilities to prepare blood components.

The number of units of blood and blood components used was slightly higher in the surgical disciplines (51\%) than in medical disciplines (49\%). This finding is similar to those of other studies [3] [7] [14]. Whole blood accounted for a higher proportion of the total blood and blood components transfused in the surgical 61.6\% (69/112) and reproductive health 76.0\% (57/75) departments and this is similar to the study by Gaur et al. [7]. This finding could be due to the fact that one of the few indications of whole blood is severe haemorrhage [15] [16] which can result from traumatic injuries seen in surgical practice and from obstetric and gynecologic complications. In this study haemorrhage accounted for $14.3 \%$ (55/384) of all the indications of transfusion, of which surgical and obstetric/gynaecologic haemorrhage comprised $78.1 \%$ (43/55) of the cases.

The top five common presenting conditions of patients requiring blood transfusion in our study were neoplasms $(23.2 \%)$, pregnancy related $(11.7 \%)$, injuries (11.4\%), infections (11.4\%) and genitourinary (9.4\%). Our findings are relatively similar to those reported in Zimbabwe [5] and Nigeria [13] [17]. The Zimbabwe study found that the top five common diagnoses were pregnancy related (22.4\%), disorders of blood and blood forming organs (17.5\%), neoplasms (10.1\%), infectious (9.0\%) and digestive diseases (8.2\%). The study by Okoroiwu et al. [13] reported diagnoses in the pregnancy \& childbirth, perinatal, genitourinary, blood and blood forming, neoplasms and injury categories as accounting for $38.9 \%, 14.4 \%, 7.9 \%, 7.8 \%, 6.7 \%$ and $4.4 \%$ respectively, of the blood and blood components issued. Studies from non-African countries have reported neoplasms, injury, digestive and circulatory systems diseases as the main diagnoses associated with transfusion [10] [18]. This strongly demonstrates that blood utilization pattern vary significantly within regions and this difference could be attributed to the variation in the clinical practices, diseases burden, lev- 
el of organization and advancement of healthcare in the different settings [1].

The finding that neoplasms was the commonest presenting condition among transfused patients in our set up could be attributed to the large number of patients with neoplasms coming to the teaching and referral hospital, as it is the only referral health facility serving Western Kenya, Eastern Uganda and South Sudan [19].

Anaemia was the most common indication of blood transfusion and this finding is similar to that of other studies [7] [9] [20]. Majority of the patients who were transfused because of anaemia could have had anaemia of chronic disease as $66.4 \%(160 / 241)$ of these patients had neoplasms, infectious and chronic renal disease which is associated with anaemia of inflammation [21]. Anaemia of chronic disease is also the most common type of anaemia among hospitalized patients [22].

In terms of the specific blood component used, whole blood was the mainly transfused to recipients with anaemia and those undergoing elective surgery and. is similar to the findings by Gaur et al. [7]. Anaemia is associated with impaired cardiac function [23] and giving these patients whole blood may cause cardiac failure due to fluid overload [24]. The recommended blood product for transfusing patients with anaemia is packed red blood cells [25] [26] as it contains minimal amounts of plasma.

The distribution of the $\mathrm{ABO}$ and Rhesus blood groups among the transfusion recipients in our study compares with that reported in the Kenyan population [27]. Blood shortage of specific blood groups is a common occurrence in Kenyan hospitals, hence making it important to understand the distribution of blood group types among transfusion recipients. This knowledge is vital in ensuring that patients requiring blood transfusion receive blood matching their $\mathrm{ABO}$ and Rhesus blood types.

One of the limitations of this study is that it was a single site study and therefore generalization of the findings may have to be taken with caution. The study also assumed that all the blood requested and issued was transfused to the patients requiring the therapy.

\section{Conclusion}

Most of the transfused patients were relatively young and were females, most of whom were in the reproductive age group. Anemia was the main indication of the transfusion and majority of the transfused recipients presented with neoplasms, pregnancy and childbirth related conditions, infections and injuries. Whole blood was the major blood component utilized and this indicates inappropriate use and unnecessary wastage of a scarce resource. Although our study presents data from a single site, the findings provide an insight into the demographic and clinical characteristics of blood transfusion recipients. The study findings also form the basis for planning more comprehensive blood utilization studies in our set up. 


\section{Conflicts of Interest}

The authors declare no conflicts of interest regarding the publication of this paper.

\section{References}

[1] World Health Organization (2017) Universal Access to Blood Transfusion. Geneva. http://www.who.int/bloodsafety/publications/UniversalAccesstoSafeBT.pdf

[2] Lim, Y.A., Lee, W.G., Cho, S.R., Hyun, B.H. and Sc, D. (2004) A Study of Blood Usage by Diagnoses in a Korean University Hospital. Vox Sanguinis, 86, 54-61. https://doi.org/10.1111/j.0042-9007.2004.00385.x

[3] Zimmermann, R., Büscher, M., Linhardt, C., Handtrack, D., Zingsem, J., Weisbach, V. and Eckstein, R. (1997) A Survey of Blood Component Use in a German University Hospital. Transfusion, 37, 1075-1083. https://doi.org/10.1046/j.1537-2995.1997.371098016449.x

[4] Biggin, K., Warner, P., Prescott, R. and McClelland, B. (2010) A Review of Methods Used in Comprehensive, Descriptive Studies That Relate Red Blood Cell Transfusion to Clinical Data. Transfusion, 50, 711-718. https://doi.org/10.1111/j.1537-2995.2009.02459.x

[5] Mafirakureva, N., Khoza, S., Hassall, O., Faragher, B.E., Kajja, I., Mvere, D.A., van Hulst, M., et al. (2015) Profiles of Blood and Blood Component Transfusion Recipients in Zimbabwe. Blood Transfusion, 13, 600-609.

[6] Pitman, J.P., Wilkinson, R., Liu, Y., von Finckenstein, B., SmitSibinga, C.T., Lowrance, D.W., Basavaraju, S.V., et al. (2015) Blood Component Use in a Sub-Saharan African Country: Results of a 4-Year Evaluation of Diagnoses Associated with Transfusion Orders in Namibia. Transfusion Medicine Reviews, 29, 45-51. https://doi.org/10.1016/j.tmrv.2014.11.003

[7] Gaur, D.S., Negi, G., Chauhan, N., Kusum, A., Khan, S. and Pathak, V.P. (2009) Utilization of Blood and Components in a Tertiary Care Hospital. Indian Journal of Hematology \& Blood Transfusion, 25, 91-95. https://doi.org/10.1007/s12288-009-0027-1

[8] Natukunda, B., Schonewille, H. and Smit Sibinga, C.T. (2010) Assessment of the Clinical Transfusion Practice at A Regional Referral Hospital in Uganda. Transfusion Medicine (Oxford, England), 20, 134-139. https://doi.org/10.1111/j.1365-3148.2010.00992.x

[9] Kuliya-Gwarzo, A. (2007) Survey of Blood Transfusion Needs in a Tertiary Nigerian Institute. Sahel Medical Journal, 10, 19-23. https://doi.org/10.4314/smj2.v10i1.12925

[10] Cobain, T.J., Vamvakas, E.C., Wells, A. and Titlestad, K. (2007) A Survey of the Demographics of Blood Use. Transfusion Medicine (Oxford, England), 17, 1-15. https://doi.org/10.1111/j.1365-3148.2006.00709.x

[11] Bosch, M.A., Contreras, E., Madoz, P., Ortiz, P., Pereira, A., Pujol, M.M. and Catalonian Blood Transfusion Epidemiology Study Group (2011) The Epidemiology of Blood Component Transfusion in Catalonia, Northeastern Spain. Transfusion, 51, 105-116. https://doi.org/10.1111/j.1537-2995.2010.02785.x

[12] World Health Organization (2017) Blood Safety and Availability. https://www.who.int/news-room/fact-sheets/detail/blood-safety-and-availability

[13] Okoroiwu, H.U. and Okafor, I.M. (2018) Demographic Characteristics of Blood and 
Blood Components Transfusion Recipients and Pattern of Blood Utilization in a Tertiary Health Institution in Southern Nigeria. BMC Hematology, 18, 16. https://doi.org/10.1186/s12878-018-0112-5

[14] Geißler, R.G., Franz, D., Buddendick, H., Krakowitzky, P., Bunzemeier, H., Roeder, N., Schlenke, P., et al. (2012) Retrospective Analysis of the Blood Component Utilization in a University Hospital of Maximum Medical Care. Transfusion Medicine and Hemotherapy, 39, 129-138. https://doi.org/10.1159/000337956

[15] Repine, T.B., Perkins, J.G., Kauvar, D.S. and Blackborne, L. (2006) The Use of Fresh Whole Blood in Massive Transfusion. The Journal of Trauma, 60, S59-S69. https://doi.org/10.1097/01.ta.0000219013.64168.b2

[16] Spinella, P.C. (2008) Warm Fresh Whole Blood Transfusion for Severe Hemorrhage: US Military and Potential Civilian Applications. Critical Care Medicine, 36, S340-S345. https://doi.org/10.1097/CCM.0b013e31817e2ef9

[17] Ughasoro, M.D., Ikefuna, A.N., Emodi, I.J., Ibeziako, S.N. and Nwose, S.O. (2013) Audit of Blood Transfusion Practices in the Paediatric Medical Ward of a Tertiary Hospital in Southeast Nigeria. East African Medical Journal, 90, 5-11.

[18] Mathoulin-Pélissier, S., Salmi, L.R., Verret, C. and Demoures, B. (2000) Blood Transfusion in a Random Sample of Hospitals in France. Transfusion, 40, 1140-1146. https://doi.org/10.1046/j.1537-2995.2000.40091140.x

[19] Armitage, I. (2013) Moi Teaching \& Referral Hospital. https://www.africaoutlookmag.com/outlook-features/moi-teaching--referral-hospital

[20] Mathew, A.S., Kurian, S.S., Sundaresan, N., Jayalekshmi, B., Prema, F.R., John, A. and Chitra, B. (2014) Pattern of Blood Component Utilization in a Teaching Hospital in South Kerala. Academic Medical Journal of India, 2, 28-31.

[21] Cullis, J.O. (2011) Diagnosis and Management of Anaemia of Chronic Disease: Current Status. British Journal of Haematology, 154, 289-300. https://doi.org/10.1111/j.1365-2141.2011.08741.x

[22] Mitlyng, B.L., Singh, J.A., Furne, J.K., Ruddy, J. and Levitt, M.D. (2006) Use of Breath Carbon Monoxide Measurements to Assess Erythrocyte Survival in Subjects with Chronic Diseases. American Journal of Hematology, 81, 432-438. https://doi.org/10.1002/ajh.20644

[23] Mozos, I. (2015) Mechanisms Linking Red Blood Cell Disorders and Cardiovascular Diseases.

[24] Shander, A., Javidroozi, M., Ozawa, S. and Hare, G.M.T. (2011) What Is Really Dangerous: Anaemia or Transfusion? British Journal of Anaesthesia, 107, i41-i59. https://doi.org/10.1093/bja/aer350

[25] Lawler, E.V., Bradbury, B.D., Fonda, J.R., Gaziano, J.M. and Gagnon, D.R. (2010) Transfusion Burden among Patients with Chronic Kidney Disease and Anemia. Clinical Journal of the American Society of Nephrology, 5, 667-672. https://doi.org/10.2215/CJN.06020809

[26] Alexandrakis, M.G. and Tsirakis, G. (2012) Anemia in Heart Failure Patients. ISRN Hematology, 2012, Article ID: 246915. https://doi.org/10.5402/2012/246915

[27] Lyko, J., Gaertner, H., Kaviti, J.N., Kariithi, M.W. and Akoto, B. (1992) Blood-Group Systems ABO and RH in the Kenyan Population. Folia Medica Cracoviensia, 33, 85-92. 